\title{
A Possible Epigenetic Mechanism for the Persistence of Memory
}

\author{
K. SI, ${ }^{*}$ S. LINDQUIST, ${ }^{\dagger}$ AND E. KANDEL ${ }^{*}$ \\ *Columbia University, Center for Neurobiology, New York, New York 10032; \\ ${ }^{\dagger}$ Whitehead Institute, Cambridge, Massachusetts 02142
}

Synaptic plasticity, the change in synaptic efficacy in response to external cues, has been shown to be one of the critical cellular mechanisms of memory storage (Bliss and Collingridge 1993; Lisman and McIntyre 2001; Morris 2003). Like behavioral memory, synaptic plasticity has at least two temporally distinct forms: a short-term form lasting minutes and a long-term form lasting days. At the molecular level long-term synaptic plasticity differs from short-term synaptic plasticity in that it requires the synthesis of new mRNA and protein (Steward and Schuman 2001; Malinow and Malenka 2002; Ehlers 2003) and is accompanied by the structural alteration of preexisting synapses and growth of new synapses (Bailey and Kandel 1993; Yuste and Bonhoeffer 2001). Even though it requires the synthesis of new mRNA in the nucleus and the nucleus is shared by all the synapses of a given cell, long-term synaptic plasticity can still be synapse specific. How could a genetic program that is cell wide give rise to synapse specificity? Work in rodents and in the marine snail Aplysia has given rise to the idea that the synapse could be selectively marked by synaptic stimulation. The synaptic marking results in either selective transport or selective utilization of plasticity-related molecules only at the marked synapse (Martin et al. 1997; Frey and Morris 1998). An early attempt to characterize the molecular nature of the synaptic mark revealed that there is a rapamycin-sensitive, local protein synthesisdependent component that is needed for the long-term maintenance of synaptic facilitation (Casadio et al. 1999).

To begin to address how synaptic change can be maintained over a long time, we focused on this rapamycinsensitive, local protein synthesis-dependent component of the synaptic mark. Since mRNAs are made in the cell body and presumably can be transported to all the synapses of a neuron, the need for the local translation of some mRNAs may reflect a requirement that these mRNAs may be dormant until they reach the activated synapse. If this were true, one way of activating synaptic protein synthesis would be to recruit a translational regulator capable of activating translationally dormant mRNAs. In search of such a molecule we focused on cytoplasmic polyadenylation element binding protein (CPEB), a molecule that activates dormant mRNAs through the elongation of their polyA tail (Mendez and Richter 2001). CPEB was first identified in oocytes and subsequently in hippocampal neurons (Hake and Richter
1994; Wu et al. 1998). However, there is a novel, neuronspecific isoform of CPEB active in the processes of marine snail Aplysia sensory neurons (Liu and Schwartz 2003; Si et al. 2003b). Stimulation with serotonin, a neurotransmitter released during learning in Aplysia, increases the amount of CPEB protein in the synapse ( $\mathrm{Si}$ et al. 2003b). The increase in the amount of CPEB coincides with the activation of mRNAs encoding synaptic structural molecules such as actin and tubulin. This CPEB isoform is not unique to Aplysia. A similar neuronal CPEB is also present in Drosophila, mice, and humans (Theis et al. 2003). In Aplysia the local activity of CPEB is needed not for the initiation or early expression of long-term facilitation, but for its long-term maintenance ( $\mathrm{Si}$ et al. 2003b). These data suggest that the maintenance, but not the initiation, of long-term synaptic plasticity requires a new set of molecules in the synapse and that some of these new molecules are made by CPEB-dependent translational activation. These results also support the idea that there are separate mechanisms for the initiation of longterm synaptic plasticity and its maintenance.

The observation that the activity of CPEB, a translation regulator, is needed not for the initiation but rather for the maintenance of long-term synaptic facilitation is quite intriguing. It raises some fundamental questions about the molecular basis of long-term synapse-specific changes: (1) Is there a continuous need for the local synthesis of a set of molecules to maintain the learning-related synaptic changes over long periods of time? (2) Is the experiencedependent molecular change of the synapse indeed maintained for a long time? (3) If so, since biological molecules (such as CPEB) have a relatively short half-life (hours to days) compared with the duration of memories (years), how is the altered molecular composition of a synapse maintained for such a long time?

A plausible answer to how unstable molecules can produce a stable change in the synaptic strength came from the subsequent finding that the neuronal isoform of CPEB shares properties with prion-like proteins ( $\mathrm{Si}$ et al. 2003a). Prions are proteins that can assume at least two stable conformational states (Prusiner 1994; Wickner et al. 1999; Uptain and Lindquist 2002). Usually one of these conformational states is active while the other is inactive. Furthermore, one of the conformational states, the prion state, is self-perpetuating, promoting the conformational conversion of other proteins of the same type. We 
have found that Aplysia neuronal CPEB exists in two stable, physical states that are functionally distinct. As with other prions, one of these states has the ability to self-perpetuate in a dominant epigenetic fashion. This dominant form is the active form of the protein capable of activating translationally dormant mRNAs.

Based on these properties of Aplysia neuronal CPEB, we propose a model for the perpetuation of long-term synapse-specific changes. We hypothesize that CPEB in the neuron has at least two conformational states: one is inactive, or acts as a repressor, while the other is active. In a naive synapse, the basal level of CPEB is low, but unlike conventional prions the protein in this state is in its inactive or repressive state. An increase in the amount of neuronal CPEB by serotonin (or other neurotransmitters), either by itself or in conjunction with other signals, triggers the conversion of CPEB to the prion-like, self-perpetuating state. The prion-like state is either more active or devoid of the inhibitory function of the basal state. Once the prion state is established in an activated synapse, dormant mRNAs that are made in the cell body and distributed globally to all synapses are activated locally through the activated CPEB. Because the activated CPEB can be selfperpetuating, it could contribute to a self-sustaining, synapse-specific, long-term molecular change and provide a mechanism for the persistence of memory.

\section{REFERENCES}

Bailey C.H. and Kandel E.R. 1993. Structural changes accompanying memory storage. Annu. Rev. Physiol. 55: 397.

Bliss T.V. and Collingridge G.L. 1993. A synaptic model of memory: Long-term potentiation in the hippocampus. Nature 361: 31 .

Casadio A., Martin K.C., Giustetto M., Zhu H., Chen M., Bartsch D., Bailey C.H., and Kandel E.R. 1999. A transient, neuron-wide form of CREB-mediated long-term facilitation can be stabilized at specific synapses by local protein synthesis. Cell 99: 221.

Ehlers M.D. 2003. Activity level controls postsynaptic composition and signaling via the ubiquitin-proteasome system. Nat. Neurosci. 6: 231.
Frey U. and Morris R.G. 1998. Synaptic tagging: Implications for late maintenance of hippocampal long-term potentiation. Trends Neurosci. 21: 181.

Hake L.E. and Richter J.D. 1994. CPEB is a specificity factor that mediates cytoplasmic polyadenylation during Xenopus oocyte maturation. Cell 79: 617.

Lisman J.E. and McIntyre C.C. 2001. Synaptic plasticity: A molecular memory switch. Curr. Biol. 11: R788.

Liu J. and Schwartz J.H. 2003. The cytoplasmic polyadenylation element binding protein and polyadenylation of messenger RNA in Aplysia neurons. Brain Res. 959: 68.

Malinow R. and Malenka R.C. 2002. AMPA receptor trafficking and synaptic plasticity. Annu. Rev. Neurosci. 25: 103.

Martin K.C., Casadio A., Zhu H., Yaping E., Rose J.C., Chen M., Bailey C.H., and Kandel E.R. 1997. Synapse-specific, long-term facilitation of aplysia sensory to motor synapses: A function for local protein synthesis in memory storage. Cell 91: 927

Mendez R. and Richter J.D. 2001. Translational control by CPEB: A means to the end. Nat. Rev. Mol. Cell Biol. 2: 521.

Morris R.G. 2003. Long-term potentiation and memory. Philos. Trans. R. Soc. Lond. B Biol. Sci. 358: 643.

Prusiner S.B. 1994. Biology and genetics of prion diseases. Annu. Rev. Microbiol. 48: 655.

Si K., Lindquist S., and Kandel E.R. 2003a. A neuronal isoform of the aplysia CPEB has prion-like properties. Cell 115: 879.

Si K., Giustetto M., Etkin A., Hsu R., Janisiewicz A.M., Miniaci M.C., Kim J.H., Zhu H., and Kandel E.R. 2003b. A neuronal isoform of CPEB regulates local protein synthesis and stabilizes synapse-specific long-term facilitation in aplysia. Cell 115: 893 .

Steward O. and Schuman E.M. 2001. Protein synthesis at synaptic sites on dendrites. Annu. Rev. Neurosci. 24: 299.

Theis M., Si K., and Kandel E.R. 2003. Two previously undescribed members of the mouse CPEB family of genes and their inducible expression in the principal cell layers of the hippocampus. Proc. Natl. Acad. Sci. 100: 9602.

Uptain S.M. and Lindquist S. 2002. Prions as protein-based genetic elements. Annu. Rev. Microbiol. 56: 703.

Wickner R.B., Edskes H.K., Maddelein M.L., Taylor K.L., and Moriyama H. 1999. Prions of yeast and fungi. Proteins as genetic material. J. Biol. Chem. 274: 555.

Wu L., Wells D., Tay J., Mendis D., Abbott M.A., Barnitt A., Quinlan E., Heynen A., Fallon J.R., and Richter J.D. 1998. CPEB-mediated cytoplasmic polyadenylation and the regulation of experience-dependent translation of alpha-CaMKII mRNA at synapses. Neuron 21: 1129.

Yuste R. and Bonhoeffer T. 2001. Morphological changes in dendritic spines associated with long-term synaptic plasticity. Annu. Rev. Neurosci. 24: 1071. 


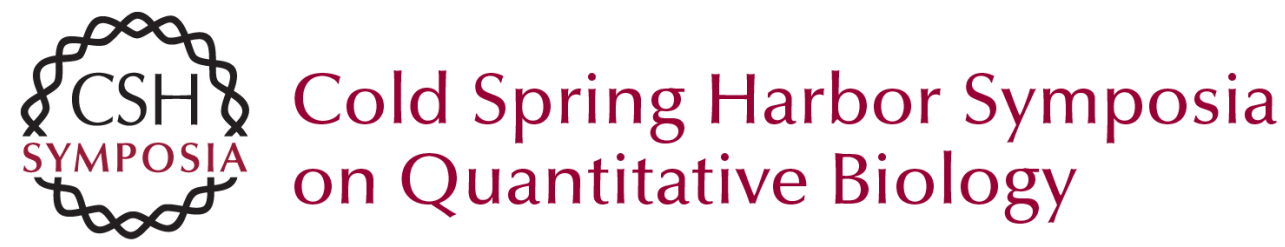

\section{A Possible Epigenetic Mechanism for the Persistence of Memory}

K. SI, S. LINDQUIST and E. KANDEL

Cold Spring Harb Symp Quant Biol 2004 69: 497-498

Access the most recent version at doi:10.1101/sqb.2004.69.497

References This article cites 21 articles, 2 of which can be accessed free at: http://symposium.cshlp.org/content/69/497.full.html\#ref-list-1

License

Email Alerting Receive free email alerts when new articles cite this article - sign up in Service the box at the top right corner of the article or click here. 